\title{
TMS: Advocating for the Importance of Science and Technology
}

\author{
Kevin J. Hemker
}

There is a growing and very real appreciation for the critical role that sci-

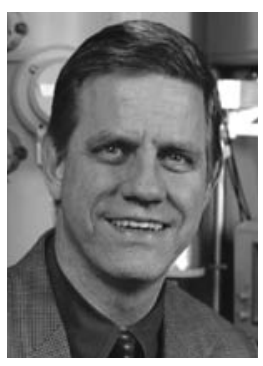
ence and technology have to play in the future of our world. The need to develop new economies, protect our environment, and address the world's ever-rising energy needs is now widely appreciated by the public at large and by those within our governments. In the United States, government officials on Capitol Hill and in the White House appear ready to invest in these priorities, and professional scientists and engineers must step forward to assure that these investments are made and that they bring about the intended results.

Scientists and engineers have been notoriously passive when it comes to engaging our government and advocating for science and technology. Given the pending crises before us, we cannot afford to remain on the sidelines. In his second book The Audacity of Hope, President Barack Obama suggested that the strength of our democracy is not that we always have the right answer but rather that no one person (king, queen, or dictator) can dictate what the right answer shall be. Dispersing the power and ensuring that various constituencies will engage in what Obama calls a "deliberative democracy" can be exhausting and infuriatingly slow at times, but it does provide a pathway to more reasonable solutions and answers. Professional societies such as TMS must participate in the debate over issues such as: scientific integrity, the environment, innovation for future economies, solutions for energy, and the future of science-technology-engi- neering-math (STEM) education.

The TMS Public \& Governmental Affairs (P\&GA) Committee has increased its footprint in advocacy in recent years. TMS is an active member of the Federation of Materials Societies and participates in Congressional Visit Days (CVD) each spring. This two-day event includes informational briefings, insider descriptions of life on the Hill, training and strategy sessions, receptions with congressional members, and visits to individual offices. Five years ago the TMS group consisted of a half dozen senior members, but the introduction of students from our Material Advantage chapters has transformed this event. Our contingent has grown to over 50 , with the vast majority being young professionals. The energy and enthusiasm of these young people make them outstanding advocates and their involvement in CVD leaves them better equipped to be public ambassadors for science and engineering.

Another recent success in the promotion of young professionals in advocacy has been the creation of Materials Societies Congressional Science and Engineering Fellows. TMS has joined with the Materials Research Society (MRS) and the American Ceramic Society to annually select and support a full-time congressional staffer. Ticora Jones of the University of Massachusetts, Amherst, was our inaugural Congressional Fellow in 2008 and is currently working in Sen. Russ Feingold's office. Ed Herderick of The Ohio State University was selected as the 2009 recipient and will start in September. This program allows us to place materials-minded staffers in congressional offices and to prepare professionals for life-long careers in materials advocacy.

Collaborations between professional societies have never been higher; the presidents and executive directors of various materials societies are regularly exploring avenues for jointly promoting materials science and engineering. The congressional fellows program is one example; another involves the use of the MRS "Materials Voice" website that allows you to contact your senators and congressional representatives on issues pertinent to the materials community. The site, which automatically provides contact information and draft messages, takes less than a minute to use and is open to all TMS members. A booth with a dedicated connection to this site will be provided at future TMS Annual Meetings, but you do not have to wait until then to check it out.

Opportunities for collaboration with a broader array of professional societies have also seen a dramatic rise in the past year. Requests to co-sign letters or position statements led us to realize that TMS needed to formulate and publish a set of guiding values for advocacy. These guiding values have been reviewed and approved by the P\&GA Committee and by the TMS Board of Directors and are posted on the TMS website (www.tms.org/PGA/PGAHome .html). I invite all members to review our advocacy guidelines and to help us assure that they remain consistent with the values of our membership.

It is an exciting and important time to be advocating for investments in materials science and engineering. All TMS members are invited to consider joining us at CVD next March, in the use of Materials Voice, or perhaps as a future member of the P\&GA Committee.

Kevin J. Hemker, Professor and Chair of the Department of Mechanical Engineering at Johns Hopkins University, is Director and Chair of the TMS Public and Governmental Affairs Committee. 